\title{
Advantages and limitations of the protein digestibility-corrected amino acid score (PDCAAS) as a method for evaluating protein quality in human diets
}

\author{
Gertjan Schaafsma* \\ Research Group on Sports, Nutrition and Lifestyle, Han University, P.O. Box 6960, 6503 GL Nijmegen, The Netherlands
}

(Submitted 27 July 2011 - Final revision received 1 November 2011 - Accepted 13 December 2011)

\section{Abstract}

PDCAAS is a widely used assay for evaluating protein quality. It is a chemical score, which is derived from the ratio between the first limiting amino acid in a test protein and the corresponding amino acid in a reference amino acid pattern and corrected for true faecal $\mathrm{N}$ digestibility. Chemical scores exceeding 100\% are truncated to $100 \%$. The advantages of the PDCAAS are its simplicity and direct relationship to human protein requirements. The limitations are as follows: the reference pattern is based on the minimum amino acid requirements for tissue growth and maintenance and does not necessarily reflect the optimum intake. Truncated PDCAAS of high-quality proteins do not give any information about the power of these proteins to compensate, as a supplement, for low levels of dietary essential amino acids in low-quality proteins. It is likely that faecal $\mathrm{N}$ digestibility does not take into account the loss from the colon of indispensable amino acids that were not absorbed in the ileum. Anti-nutritional factors, such as lectins and trypsin inhibitors, in several plant protein sources can cause heightened endogenous losses of amino acids, an issue which is particularly relevant in animal feedstuffs. The assumption that amino acid supplementation can completely restore biological efficiency of the protein source is incorrect since the kinetics of digestion and absorption between supplemented free amino acids and amino acids present in dietary proteins, are different.

\section{Key words: Protein quality: PDCAAS: Advantages: Limitations: Improvements}

Dietary proteins differ in their capacity to satisfy the metabolic demand for the nine dietary indispensable amino acids and nitrogen. Digestibility and the extent to which the absorbed amino acid pattern matches that of the requirement pattern are critical for the nutritional quality of single proteins and protein mixtures. In the past, protein quality was measured merely in growth experiments with rats and expressed in parameters like PER (Protein Efficiency Ratio) and NPU (Net Protein Utilization). The PER compares the growth response of young rats, fed a marginal amount of a test protein, with that of control rats, fed a similar amount of casein, and the NPU is in fact the product of Digestibility (digestion and absorption) and Biological Value (the amount of utilized nitrogen divided by the amount of absorbed nitrogen). The main disadvantage of these methods is that the rat amino acid requirement pattern is not identical to that of humans and therefore the only correct measure of protein quality is nitrogen balance evaluation in humans. This is however too expensive for routine use. Therefore, in 1989 a FAO/WHO Expert Consultation ${ }^{(1)}$ on protein quality evaluation concluded that protein quality could be adequately assessed by expressing the content of the first limiting indispensable amino acid in the test protein as a fraction of the content of the corresponding amino acid in an age specific 'ideal' reference pattern and subsequently by multiplying this amino acid score by true faecal $\mathrm{N}$ digestibility (\%), as measured in a rat assay.

$$
\begin{aligned}
\operatorname{PDCAAS}(\%)= & \text { amino acid score }(\mathrm{AAS}) \\
& \times \text { true } \mathrm{N} \text { digestibility }(\mathrm{TD})(\%)
\end{aligned}
$$

$$
\begin{aligned}
\text { AAS }= & \text { Content of first limiting amino acid in a test } \\
& \text { protein }(\mathrm{mg} / \mathrm{g}) / \text { Content of corresponding } \\
& \text { amino acid in a reference protein }(\mathrm{mg} / \mathrm{g})
\end{aligned}
$$

The reference amino acid pattern in the reference protein was obtained by dividing the indispensable amino acid requirements of the preschool child $(\mathrm{mg} / \mathrm{kg})$ by the safe level of (high quality) protein intake $(\mathrm{g} / \mathrm{kg})$ of this age group. PDCAAS-scores exceeding $100 \%$ were truncated to $100 \%$. PDCAAS is now widely used as a routine assay for the assessment of the quality of single proteins and protein mixtures.

Since its introduction in $1991^{(1)}$, the PDCAAS has been the subject of criticism $^{(2)}$. This referred to the following issues: the validity of the scoring pattern, the truncation to $100 \%$, the use of faecal vs. ileal digestibility, impact of anti nutritional factors in protein sources and the suitability of PDCAAS in predicting the quality of amino acid-supplemented proteins.

*Corresponding author: G. Schaafsma, email Gertjan.schaafsma@online.nl 
Several of these issues have been discussed in the 2007 report of the joint $\mathrm{WHO} / \mathrm{FAO} / \mathrm{UNU}$ Expert Consultation on protein and amino acid requirements in human nutrition ${ }^{(3)}$.

This contribution reviews the current status of PDCAAS, including its advantages and limitations. It also proposes an additional protein quality index.

\section{PDCAAS critical issues}

\section{Truncation of the amino acid score}

In the $1991 \mathrm{FAO} / \mathrm{WHO}$ report on protein quality assessment ${ }^{(1)}$, PDCAAS values exceeding $100 \%$ were truncated to $100 \%$. It has been put forward ${ }^{(2)}$ that truncation does not give credit for the extra dietary indispensable amino acids in high-quality supplementary proteins that are used to balance the amino acid composition of a mixed diet, which is a nutritionally relevant intrinsic value of high-quality proteins. This was recognized in the $2007 \mathrm{FAO} / \mathrm{WHO} / \mathrm{UNU}$ report ${ }^{(3)}$. In that report it was clarified that Biological Value, e.g. utilization of absorbed dietary essential and non essential amino acids, cannot exceed the value 1 and that therefore amino acid scores and not the final PDCAAS-values of dietary proteins (as proposed in the 1991 report) should be truncated to 1 . This means that in cases where amino acid scores exceed the value 1, PDCAASvalues are equal to True Digestibility.

The limitation of PDCAAS-values, resulting from truncated amino acid scores, and thus not giving credit for the extra indispensable amino acids, is admitted in the $2007 \mathrm{WHO} /$ FAO/UNU report ${ }^{(3)}$. This report suggests that this limitation can be overcome by the development of an additional protein quality index, in which the contents of the essential amino acids that are most often limited in single proteins (e.g. lysine (cereals), sulphur amino acids (legume proteins), threonine (some cereals) and tryptophan (maize)), are represented. Such an index (which could be called supplementation power: SP) for a particular protein can be obtained easily by multiplying the score of each of these amino acids with true digestibility values. An example is given in Table 1.

From the data shown in Table 1, it can be computed that $1.28 \mathrm{~g}$ of milk protein is needed to balance $1 \mathrm{~g}$ of the lysine deficient wheat protein. The formula for this is: amount of milk protein $(\mathrm{g})=(1$-LSPwheat $) /($ LSPmilk-1), where LSP wheat $=$ lysine supplementation power of wheat and LSP milk = lysine supplementation power of milk. To balance this wheat protein with chick pea, one would need $8.5 \mathrm{~g}$ of this protein.

Table 1. Supplementation power (SP) of different proteins to balance diets deficient in lysine, sulphur amino acids (SAA), threonine or tryptophan.

\begin{tabular}{lccc}
\hline & Milk powder & Chick pea & Wheat \\
\hline Lysine & 1.46 & 1.07 & 0.41 \\
SAA & 1.22 & 0.77 & 1.14 \\
Threonine & 1.30 & 1.24 & 0.94 \\
Tryptophan & 1.54 & 1.41 & 1.26 \\
\hline SP values (non-truncated amino acid score x true digestibility), obtained from data \\
on amino acid content, true digestibility values and 1-2 year old children amino \\
acid scoring pattern, as reported by WHO/FAO/UNU
\end{tabular}

\section{Validity of the scoring patterns}

Amino acid scoring patterns ( $\mathrm{mg} / \mathrm{g}$ protein) are obtained by dividing dietary essential amino acid requirements $(\mathrm{mg} / \mathrm{kg}$ body weight) by the minimum amount of protein needed for adequate growth and maintenance ( $\mathrm{g} / \mathrm{kg}$ body weight). They depend on age, physiological status and health status. The 1989 FAO/WHO Expert Consultation ${ }^{(1)}$ on protein quality evaluation realized that age specific amino acid requirement patterns, that existed at that time, were based on limited evidence and therefore it was proposed for PDCAAS purposes to use, as an interim procedure, the $1985 \mathrm{WHO} / \mathrm{FAO} / \mathrm{UNU}^{(4)}$ amino acid requirement pattern of the preschool child. This pattern however did not represent the pattern of normal healthy children, since it was obtained from a limited number of children that were recovering from malnutrition. It was therefore assumed (but not validated) that this requirement pattern reflected upper requirement levels of normal healthy children. Instead of dividing the pattern by the minimum protein requirement, it was divided by the safe level of (high-quality) protein intake. Since that time knowledge about age-specific amino acid requirements has increased. Therefore, in the $2007 \mathrm{WHO} / \mathrm{FAO} / \mathrm{UNU}$ report $^{(3)}$, revised amino acid scoring patterns were published for different age groups. These patterns were obtained by dividing essential amino acid requirements by minimum requirements of highquality proteins, which is the correct procedure. Table 2 shows the patterns for three different age groups ( 0.5 years, 1-2 years and adults). For age groups between 1-2 years and adults, intermediate values were published. The slight decreases in content of essential amino acids with advancing age are attributable to differences in requirement values for maintenance and growth and the relative decrease of requirements for growth with aging.

Scoring patterns are thus based on minimum requirements of normal healthy subjects. They do not necessarily represent optimal protein nutrition. The PDCAAS approach argues that increased amino acid oxidation reflects inefficient use of amino acids, but this ignores roles of amino acids beyond requirements for maintenance and growth, such as any transient signalling influence before oxidation ${ }^{(5)}$. An example of this is the signalling function of leucine in stimulating muscle protein synthesis ${ }^{(6)}$. Other examples are effects on

Table 2. Age-specific amino acid scoring patterns ( $\mathrm{mg} / \mathrm{g}$ protein).

\begin{tabular}{lccc}
\hline & \multicolumn{3}{c}{ Age group (years) } \\
\cline { 2 - 4 } & 0.5 & $1-2$ & $>18$ \\
\hline His & 20 & 18 & 15 \\
lle & 32 & 31 & 30 \\
Leu & 66 & 63 & 59 \\
Lys & 57 & 52 & 45 \\
SAA & 28 & 26 & 22 \\
AAA & 52 & 46 & 38 \\
Thr & 31 & 27 & 23 \\
Trp & 8.5 & 7.4 & $6 \cdot 0$ \\
Val & 43 & 42 & 39 \\
Total & 337.5 & 312.4 & $277 \cdot 0$ \\
\hline
\end{tabular}

From WHO/FAO//UNU ${ }^{(3)}$. 
satiation and satiety ${ }^{(7)}$ and the power of sulphur amino acids to increase the synthesis of glutathione and taurine ${ }^{(8)}$. The scoring pattern is also unlikely to represent all situations where an additional need for specific amino acids may exist, such as in pregnancy, lactation, old age, the negative energy balance during calorie restriction, clinical conditions and in sports people. Conditionally indispensable amino acids are not included in PDCAAS, so it is uncertain that PDCAASvalues are applicable in situations where a special need for these amino acids may exist, like in pathological conditions or extreme physiological situations.

\section{Ileal vs. Faecal Digestibility}

True faecal $\mathrm{N}$ digestibility does not take into account essential amino acids that are not absorbed in the ileum and are lost into the colon. This is an important route for metabolic consumption of amino acids by the intestinal flora. Based on studies in humans, Gaudichon et al. ${ }^{(9)}$ suggested that ileal losses of amino acids are an important component of amino acid requirements. True faecal $\mathrm{N}$ digestibility values in the rat also potentially overestimate digestibility because of coprophagy.

A low ileal protein digestibility, which thus increases the flow of nitrogen into the colon, increases the bacterial formation of toxic compounds, such as ammonia, phenols and indoles. For these reasons the use of ileal digestibility in fistulated pigs, instead of faecal digestibility in rats, has been proposed as a better approach for the assessment of PDCAAS values $^{(2,10)}$. The advantage of using pigs is also that the gastro-intestinal physiology of this meal-eating species resembles more closely that of humans. It should be stressed, however, that the possibility of recycling of colonic and bacterial amino acids into the body has not been studied ${ }^{(11)}$. Recently Deglaire et al. ${ }^{(12)}$, compared the ileal digestibility of dietary protein in the ileal fistulated growing pig and ileal sampled adult human. Their results supported the use of pigs as a model for predicting differences among dietary ileal protein digestibilities.

\section{Amino acid availability}

Current PDCAAS assessment does not take into account potential differences in bioavailabilty between amino acids from a food protein source, so processing or storage of foods at higher temperatures may selectively decrease the bioavailability of lysine by Maillard reactions ${ }^{(13)}$. Routine amino acid analysis does not identify the biologically inactive D-amino acids that can be formed by racemization from L-amino acids through heat treatment under alkaline conditions. Oxidized sulphur amino acids are less bioavailable, and their presence in a food protein source may lead to overestimation of its PDCAAS. Another issue here is the supplementation of a food protein source with its limiting free amino acid to increase its PDCAAS. Such a supplementation may however not improve PDCAAS to the desired level. This has been demonstrated for leucine. Nolles ${ }^{(14)}$ showed that, because of different absorption kinetics, supplemented (extrinsic) leucine is preferentially oxidized compared to its intrinsic form.

\section{Anti-nutritional factors}

Anti-nutritional factors, such as trypsin inhibitors, tannins and lectins, are often present in plant food protein sources. They may inhibit protein digestion and/or increase endogenous nitrogen losses into the faeces, causing a decrease in the apparent protein digestibility and an increase of protein requirements ${ }^{(15,16)}$. Such effects are not included in the PDCAAS and this score thus overestimates the protein quality of products containing these naturally occurring anti-nutritional factors. The endogenous nitrogen flow into the ileum of pigs was $1 \cdot 3,3 \cdot 1,3 \cdot 3,4 \cdot 0$ and $10 \cdot 8 \mathrm{~g} / 100 \mathrm{~g}$ protein for skim milk, wheat, soya protein isolate, barley and phaseolus beans respectively ${ }^{(17)}$. Processing may decrease but not completely eliminate the activity of anti-nutritional factors ${ }^{(18,19)}$. In feedstuffs (less processing) the problem is more important than in foods.

\section{Requirement for an animal experiment}

Although PDCAAS is a rapid and relatively cheap routine method for the assessment of protein quality, it still needs an animal experiment for the measurement of true $\mathrm{N}$ digestibility. Considering the negative public opinion on the use of animals for research, it would be an advantage when protein quality measurement could be performed in-vitro. As shown before ${ }^{(2)}$, true ileal digestibility of dietary essential amino acids can be measured in a computer-controlled dynamic digestion system. The advantage of such a system is that it can mimic physiological conditions of different animal species, so that it becomes possible to assess speciesspecific ileal amino acid digestibility coefficients.

\section{Conclusions}

PDCAAS is a useful routine assay for the protein quality assessment of single proteins and proteins in mixed diets for normal healthy subjects, in spite of a number of limitations and disadvantages. The disadvantage of truncation can be overcome by the use of an additional protein quality score which takes into account the power of a protein to balance diets which are deficient in one or more indispensable amino acid. The measurement of true faecal protein digestibility in rats should be replaced by a measurement of true ileal protein digestibility or (preferentially) true ileal indispensable amino acid digestibility in ileal-fistulated pigs or by an in-vitro measurement. It remains to be established whether currently used reference amino acid scoring patterns, which are derived from minimum dietary indispensable amino acid requirements and minimum requirements of high-quality protein of normal healthy subjects, reflect intake levels of amino acids for optimal health and are applicable in situations of disease and/or specific or extreme physiological situations. 


\section{Acknowledgements}

G.S. is the only author of this paper. The author states that there is no conflict of interest. The research received no specific grant from any funding agency in the public, commercial and/or not for profit area.

\section{References}

1. FAO/WHO Expert Consultation (1991) Protein quality evaluation. Food and Agricultural organization of the United Nations, FAO Food and Nutrition Paper no. 51, Rome.

2. Schaafsma G (2005) The protein digestibility-corrected amino acid score (PDCAAS) - a concept for describing protein quality in foods and food ingredients: a critical review. Journal of AOAC International 88, 988-994.

3. WHO/FAO/UNU Expert Consultation (2007) Protein and amino acid requirements in buman nutrition. WHO Technical reports Series no. 935. Geneva: World Health Organization.

4. WHO/FAO/UNU Expert Consultation (1985) Energy and protein requirements. WHO Technical Report no. 724. Geneva: World Health Organization.

5. Millward J, Layman DK, Tomé D, et al. (2008) Protein quality assessment: impact of expanding understanding of protein and amino acid needs for optimal health. American Journal of Clinical Nutrition 87, 1576S-1581S.

6. Layman DK (2003) The role of leucine in weight loss diets and glucose homeostasis. Journal of Nutrition $\mathbf{1 3 3}$, 261S-267S.

7. Tome D (2004) Protein, amino acids and the control of food intake. British Journal of Nutrition 92, S27-S30.

8. Schaafsma G (2008) Sulfur in human nutrition; effects beyond protein synthesis. Nutrafoods 7, 5-10.

9. Gaudichon C, Bos C, Morens C, et al. (2002) Ileal losses of nitrogen and amino acids in humans and their importance to the assessment of amino acid requirements. Gastroenterology 123, 50-59.
10. Darragh AJ \& Hodgkinson SM (2000) Quantifying the digestibility of dietary protein. Journal of Nutrition 130, 1850S-1856S.

11. Fuller MF \& Tomé D (2005) In vivo determination of amino acid bioavailability in humans and model animals. Journal of AOAC International 88, 923-934

12. Deglaire DA, Bos C, Tomé D, et al. (2009) Ileal digestibility of dietary protein in the growing pig and adult human. British Journal of Nutrition 102, 1752-1759.

13. Moughan PJ (2005) Absorption of chemically ummodified lysine from proteins in foods that have sustained damage during processing or storage. Journal of AOAC International 88, 949-954.

14. Nolles JA (2006) Postprandial fate of amino acids; adaptation to molecular forms. Thesis, Wageningen University and Research Center, Wageningen, The Netherlands.

15. Van Leeuwen P, Veldman A, Boisen S, et al. (1996) Apparent ileal dry matter and crude protein digestibility of rations fed to pigs and determined with the use of chromic oxide (Cr2O3) and insoluble ash as digestive markers. British Journal of Nutrition 76, 551-562.

16. Huisman J, Verstegen MWA, van Leeuwen P, et al. (1993) Reduction of $\mathrm{N}$ pollution by decrease of the excretion of endogenous nitrogen in pigs. In Nitrogen flow in pig production and environmental consequences, pp. 55-61. Wageningen, The Netherlands: Pudoc Scientific Publishers.

17. Souffrant JM (2001) Endogenous nitrogen losses during digestion in pigs. In Digestive physiology in pigs, pp. 147-166, EAAP publication no 54 [MWA Verstegen, J Huisman and E Den Hartog, editors]. Wageningen, The Netherlands: Pudoc scientific publishers.

18. Liu KS (2006) Composition of identity-preserved soy beans. In: United States Expert Council, Technical aspects of identity-preserved system for soy beans in the United States. Chapter 5. www.ussoyexports.org.

19. Yuan S, Chang SK, Liu Z, et al. (2008) Elimination of trypsin inhibitor activity and beany flavor in soy milk by consecutive blanching and ultrahigh temperature (UHT) processing. Journal of Agriculture and Food Chemistry 56, 7957-7963. 